\title{
Fetal Bile Salt Metabolism
}

\section{THE INTESTINAL ABSORPTION OF BILE SALT}

\author{
R. Lester, R. A. Smallwood, J. M. Little, A. S. Brown, G. J. Piasecki, \\ and B. T. JACKSON
}

From the Department of Medicine, University of Pittsburgh School of Medicine, Pittsburgh, Pennsylvania 15261; the Department of Surgery, Boston University Medical Center, and the Surgical Service, Boston Veterans Administration Hospital, Boston, Massachusetts 02118

A B S T RACT The intestinal absorption of sodium taurocholate was studied in the near-term fetal and neonatal dog. Absorption rates were measured in vivo in isolated loops of fetal jejunum and ileum. Absorption was also measured in vitro in everted sacs and rings of fetal and neonatal jejunum and ileum.

The maximal rates of taurocholate absorption observed after instillation of $1 \mu \mathrm{mol}$ taurocholate into closed segments of fetal jejunum and ileum with intact blood supply were not significantly different $(P>0.2)$, and equalled $0.282 \pm 0.026$ (mean \pm SEM) and $0.347 \pm 0.051 \mu \mathrm{mol} / \mathrm{h}$ per $10-\mathrm{cm}$ segment length jejunum and ileum, respectively. Similarly, the rates of absorption from open segments of jejunum and ileum perfused with 0.4 and $1.0 \mathrm{mM}$ taurocholate were nearly identical $(0.232 \pm 0.040$ and $0.255 \pm 0.039$, respectively at $0.4 \mathrm{mM}$, and $0.470 \pm 0.065$ and 0.431 \pm 0.013 , respectively at $1.0 \mathrm{mM})(P>0.2)$. At perfusate concentrations of $4.0 \mathrm{mM}$, moreoever, jejunal absorption exceeded ileal absorption $(1.490 \pm 0.140$ and $0.922 \pm 0.200$, respectively $)(P<0.05)$.

As expected, concentration of taurocholate by the mucosa was readily demonstrated in adult ileal, but not in adult jejunal everted rings. In contrast, there were no significant differences in mucosal uptake of taurocholate by fetal jejunal and ileal rings. Fetal ileal mucosal concentrations were not significantly above those in the incubation medium after 1-h exposure of the mucosa to $0.003,0.03$, and $0.3 \mathrm{mM}$ taurocholate. Uptake was proportional to incubation medium concentration over the full range of values.

Received for publication 1 April 1976 and in revised form 28 January 1977.
This was also true of tissues from 1-wk-old neonates. However, by 2 wk of age, ileal mucosal concentration of taurocholate was evident and adult levels were attained by 5 wk of age.

It is concluded that taurocholate is absorbed by the fetal gut and that ileal absorption is no more efficient than jejunal absorption. Although active glucose transport was demonstrable in both jejunum and ileum, it was not possible to demonstrate an ileal mechanism for active transport of taurocholate in the fetus. Active ileal transport was not demonstrable in the newborn until at least $2 \mathrm{wk}$ after birth.

\section{INTRODUCTION}

The enterohepatic circulation of bile salts has been studied in adults of different species (1-3). It is well established that bile salts are synthesized and conjugated in the liver, secreted into bile, concentrated in the gall bladder, and then discharged into the intestine. Conjugated bile salts are sparingly absorbed from the jejunum, but active, carriermediated absorption is demonstrable in the ileum. Absorbed bile salts are cleared from the portal blood by the liver and resecreted in bile. Thus, the enterohepatic circulation provides an efficient mechanism for the conservation and reutilization of bile salt.

Although other aspects of the fetal synthesis and utilization of bile salt have been studied (4-6), fetal intestinal bile salt absorption has not previously been investigated. In the present study, the fetal intestinal absorption of taurocholate was examined in vivo and in vitro. Active ileal transport was not demonstrable in the fetus and did not develop until at least 2 wk after birth. 


\section{METHODS}

\section{Surgical preparation of fetuses}

Experiments were carried out in fetuses from pregnant pedigree beagles 1-3-yr old between the 56th and 58th day of pregnancy (total period of gestation, 63 days). All animals were worm-free and vaccinated against canine distemper and hepatitis. The mother was anesthetized with thiamylal sodium intravenously, and anesthesia was maintained with a halothane-oxygen mixture in a nonrebreathing system using an intermittent positive pressure respirator. Maternal temperature was monitored throughout the study and was maintained at $36 \pm 1^{\circ} \mathrm{C}$. A midline laparotomy was performed, and a portion of the uterus containing a suitably positioned fetus was exposed. Electrocardiographic leads were implanted through the uterine wall in two forelegs and one hindleg of the fetus (7).

In all in vivo experiments $\left(\mathrm{FD}_{1-18}\right),{ }^{1}$ a cannula was placed in the fetal common bile duct $(4,5)$ through a "marsupializing" incision in the right subcostal region as previously described (8). In whole gut instillation experiments $\left(F D_{1-3}\right)$, a polyvinyl catheter (OD, 0.023 inches; ID, 0.011 inches) was placed in the small bowel at the duodeno-jejunal flexure, and the lumen was tied off proximally. The bowel was left otherwise intact. In segmental instillation experiments $\left(\mathrm{FD}_{4-11}\right)$, jejunum and ileum were identified, and approximately $10 \mathrm{~cm}$ of either proximal jejunum or distal ileum was isolated from the rest of the bowel, keeping the vascular supply of the isolated segment intact. The distal end of the segment was tied off and the proximal end was cannulated (polyvinyl catheter, OD, 0.023 inches; ID, 0.011 inches). In perfusion experiments $\left(F D_{12-18}\right), 10-\mathrm{cm}$ jejunal and ileal segments were isolated and cannulated proximally as above. A second catheter (OD, 0.125 inches; ID, 0.078 inches) was placed distally to allow circulation of the perfusing fluid. In all experiments, fetal and maternal incisions were subsequently closed, and the fetus was released from its attachment to the uterus and left free within the amniotic space.

In in vitro experiments $\left(\mathrm{FD}_{19-32}, \mathrm{ND}_{1-12}\right)$, the fetal or neonatal gut was exposed through an extended right subcostal incision. The small bowel was filled in situ with iced Krebs-Ringer phosphate buffer, stripped from its mesentery, and then removed. The lumen was flushed clean with additional buffer and the proximal $10 \mathrm{~cm}$ of jejunum and distal $10 \mathrm{~cm}$ of ileum were separated, identified, and then placed in iced Krebs-Ringer phosphate. Each gut segment was rinsed with additional cold buffer and everted rings or sacs were prepared. The procedure for adult controls $\left(\mathrm{AD}_{1-10}\right)$ was essentially the same except that $20-\mathrm{cm}$ intestinal segments were isolated before being filled with Krebs-Ringer phosphate.

\section{Preparation of radio-labeled bile salts}

$\left[{ }^{14} \mathrm{C}\right]$ Taurocholate was prepared by biosynthesis as described previously (4) from chromatographically pure $\left[24^{14} \mathrm{C}\right]$ cholate (New England Nuclear, Boston, Mass.). Commercially obtained $\left[24-{ }^{14} \mathrm{C}\right]$ taurocholate (Mallinckrodt Inc., St. Louis, Mo.) and $\left[{ }^{3} \mathrm{H}\right]$ taurocholate (generally labeled,

\footnotetext{
${ }^{1}$ Organization of experiments: $\mathrm{FD}_{1-18}$, in vivo experiments; $\mathrm{FD}_{1-3}$, whole gut instillation experiments; $\mathrm{FD}_{4-11}$, segmental instillation experiments; $F D_{12-18}$, perfusion experiments; $\mathrm{FD}_{19-32}$, in vitro experiments; $\mathrm{ND}_{1-12}$, in vitro experiments; $\mathrm{AD}_{1-10}$, adult controls.
}

New England Nuclear) were purified by reversed-phase chromatography on Sephadex LH-20 (Pharmacia Fine Chemicals, Piscataway, N. J.) using water/butanol (3:1) (9). The purity of the selected bile salts was established by thinlayer chromatography in three systems: (a) chloroform/ methanol/acetic acid/water $(65: 20: 10: 5) ;(b)$ butanol/acetic acid/water (85: 10:5); and (c) isoamyl acetate/propionic acid/ $n$ propanol/water $(4: 3: 2: 1)(10)$.

\section{Experimental design}

In vivo. In all studies, the experimental period began shortly after the completion of surgery. Light halothane anesthesia was maintained, and the mother was infused with $5.0 \%$ dextrose in $0.9 \%$ sodium chloride at $50 \mathrm{ml} / \mathrm{h}$. The fetal heart rate and electrocardiogram were monitored during the course of study and remained stable.

In $\mathrm{FD}_{1-11}, 1 \mathrm{ml}$ of sodium $\left[{ }^{14} \mathrm{C}\right]$ taurocholate $(1 \mathrm{mM}$ in $0.9 \%$ sodium chloride, $\mathrm{pH}$ adjusted to 7.0 with $0.1 \mathrm{~N}$ sodium hydroxide) was instilled into the fetal gut, and its absorption was measured by the rate of appearance of radioactivity in the fetal bile. In $\mathrm{FD}_{1-3}$, absorption was studied from the "whole gut," i.e., after instillation of the test solution distal to the duodeno-jejunal junction. Absorption was studied in $F_{4-8}$ from an isolated jejunal segment, and in $F D_{9-11}$ from an isolated ileal segment. Experiments were continued until excretion of radioactivity in fetal bile had fallen to low levels or ceased.

In $F_{12-18}$, segments of fetal gut were perfused with varying concentrations of $\left[{ }^{14} \mathrm{C}\right]$ taurocholate. The perfusion system consisted of a reservoir containing $100 \mathrm{ml}$ of the perfusate connected by polyvinyl tubing (with a side arm for pressure monitoring) to a roller pump which delivered a constant volume flow to the gut. In each experiment, either a jejunal $\left(F D_{12-15}\right)$ or an ileal $\left(\mathrm{FD}_{16-18}\right)$ segment was perfused with sodium $\left[{ }^{14} \mathrm{C}\right.$ ] taurocholate in $0.9 \% \mathrm{NaCl}$ containing $1 \%$ polyethylene glycol, and absorption of bile salt was followed by monitoring appearance of $\left[{ }^{14} \mathrm{C}\right]$ taurocholate in fetal bile. Perfusate leaving the gut by way of the distal catheter was collected at times corresponding to the bile collections. The perfusion rate was $0.45 \mathrm{ml} / \mathrm{min}$ and the priming volume of the system was $5.0-6.5 \mathrm{ml}$ with $2.5 \mathrm{ml}$ catheter volume. Initial taurocholate perfusion concentrations were $0.4 \mathrm{mM}$. When the excreted label had remained constant for at least $1 \mathrm{~h}$, the $0.4 \mathrm{mM}$ taurocholate solution was replaced by a $1.0 \mathrm{mM}\left[{ }^{14} \mathrm{C}\right]$ taurocholate solution. The cycle was repeated, and when the steady-state conditions had once more been established, a $4.0 \mathrm{mM}$ solution of $\left[{ }^{14} \mathrm{C}\right]$ taurocholate was substituted as the perfusate. At the end of each experiment, the preparation was sacrificed and samples of fetal tissues and maternal liver and gall bladder bile were kept for analysis of radioactivity.

In vitro. In three fetuses $\left(\mathrm{FD}_{19-21}\right)$, everted gut sacs of jejunum and ileum $10 \mathrm{~cm}$ in length were prepared. The sacs were filled until moderately distended with $1.0-2.5 \mathrm{ml}$ of $100 \mathrm{mg} / 100 \mathrm{ml}$ glucose in Krebs-Ringer phosphate buffer, pH 6.5 (serosal side), and incubated in $15 \mathrm{ml}$ of the same solution with $0.003 \mathrm{mM}$ sodium $\left[{ }^{3} \mathrm{H}\right]$ taurocholate, giving a final concentration of radiolabel of approximately 10,000$20,000 \mathrm{dpm} / \mathrm{ml}$ (mucosal side). Sacs were incubated in stoppered $50-\mathrm{ml}$ Erlenmeyer flasks at $37^{\circ} \mathrm{C}$ in a shaking water bath for $1 \mathrm{~h}$ in an atmosphere of $95 \%$ oxygen-5\% carbon dioxide which had been bubbled through the incubating medium just before the incubation. After $1 \mathrm{~h}$, the sacs were blotted dry, fluid from the serosal compartment was collected, and the volume was measured. Fluid contained within the sacs (serosal fluid) and incubation fluid (musocal fluid) were assayed for radioactivity and glucose concentra- 
TABLE I

Distribution of Radiolabel after Instillation of Sodium $\left[{ }^{14} \mathrm{C}\right]$ Taurocholate into Fetal Gut in Vivo

\begin{tabular}{|c|c|c|c|c|c|c|c|}
\hline \multirow[b]{2}{*}{ Experiment } & \multirow{2}{*}{$\begin{array}{l}\text { Duration of } \\
\text { experiment }\end{array}$} & \multirow[b]{2}{*}{ Segment studied } & \multicolumn{3}{|c|}{ Fetal } & \multirow{2}{*}{$\begin{array}{c}\text { Matemal } \\
\text { bile }\end{array}$} & \multirow[b]{2}{*}{ Total } \\
\hline & & & Bile & Liver & Gut & & \\
\hline & $h$ & & & $\%^{*}$ & & $\%^{*}$ & $\%^{*}$ \\
\hline$F_{1}$ & 5.3 & Intact gut & 84.8 & 5.0 & 8.0 & - & 97.9 \\
\hline 2 & 3.5 & Intact gut & 81.4 & 0.8 & 4.0 & - & 86.2 \\
\hline 3 & 3.3 & Intact gut & 81.9 & 2.0 & 2.2 & - & 86.1 \\
\hline 4 & 3.0 & Jejunum & 64.4 & - & 8.6 & - & 73.0 \\
\hline 5 & 3.7 & Jejunum & 69.9 & - & 12.7 & 0.5 & 83.1 \\
\hline 6 & 2.7 & Jejunum & 76.1 & - & 12.3 & 0.2 & 88.6 \\
\hline 7 & 4.0 & Jejunum & 68.6 & 8.0 & - & 0.5 & 77.1 \\
\hline 8 & 4.0 & Jejunum & 83.6 & 4.5 & 6.5 & - & 94.6 \\
\hline 9 & 3.7 & Ileum & 85.6 & - & 2.1 & 0.4 & 88.1 \\
\hline 10 & 4.3 & Ileum & 97.1 & - & - & 0.2 & 97.3 \\
\hline 11 & 4.0 & Ileum & 95.4 & 1.4 & 0.3 & - & 97.1 \\
\hline
\end{tabular}

* Percent of dose.

tion. The gut wall was also homogenized and assayed for radioactivity.

In 11 fetuses $\left(F D_{22-32}\right), 12$ newborns $\left(\mathrm{ND}_{1-12}\right)$, and 10 adults $\left(A D_{1-10}\right)$, everted gut rings $(3-4 \mathrm{~mm}$ in width in fetuses and neonates; $10 \mathrm{~mm}$ in width in adults) were prepared from jejunum and ileum. Rings from each section of gut were distributed in three 25-ml Erlenmeyer flasks (8-10 rings per flask in fetal studies; 4-6 rings per flask in newborn studies; 2 rings per flask in adult studies) containing $15 \mathrm{ml}$ of $0.003,0.03$, or $0.3 \mathrm{mM}\left[{ }^{3} \mathrm{H}\right]$ taurocholate in KrebsRinger phosphate with $100 \mathrm{mg} / 100 \mathrm{ml}$ glucose and tracer quantities of polyethylene-[1,2-14 $\mathrm{C}]$ glycol (mol wt, 4,000) as a marker of extracellular fluid. The flasks were gassed for $1 \mathrm{~min}$ with $95 \%$ oxygen-5\% carbon dioxide, stoppered, and then incubated at $37^{\circ} \mathrm{C}$ in a shaking water bath for $1 \mathrm{~h}$. After $1 \mathrm{~h}$, the rings were rinsed in fresh buffer and blotted dry. Tissues and incubation fluid samples were kept frozen for later analysis.

\section{Analytical procedures}

Radioactivity in bile and other fluids was assayed in a Packard Tri-Carb liquid scintillation spectrometer (Packard Instrument Co., Inc., Downers Grove, Ill.) as previously described (11). Fetal intestinal tissue, adult intestinal mucosa, and other solid tissues were homogenized and counted either directly in a xylene-based solubilizer cocktail or, after digestion, in a standard toluene-based cocktail. Bile samples were subjected to thin-layer chromatography to characterize the radioactive components of bile. These were assayed for radiolabel as previously described (4). Polyethylene glycol was measured in the perfusing fluid spectrophotometrically (12). Glucose concentrations were measured using glucose oxidase (13).

Mucosa from everted gut rings was homogenized and counted for $\left[{ }^{3} \mathrm{H}\right]$ taurocholate and $\left[{ }^{14} \mathrm{C}\right]$ polyethylene glycol. The mucosal concentrations of $\left[{ }^{3} \mathrm{H}\right]$ taurocholate were corrected for extracellular fluid volume (14) and compared with concentrations in the incubation medium.

\section{RESULTS}

Instillation experiments, $F D_{1-11}$. Preliminary studies were carried out by injection of a single concentration of $\left[{ }^{14} \mathrm{C}\right]$ taurocholate into the fetal intestine through a catheter implanted at the duodenojejunal flexure. Although the small amounts of radiolabel found in fetal tissues and maternal bile represented an additional absorbed fraction, absorption of taurocholate was approximated by measuring the appearance of radiolabel in fetal hepatic bile (Table I). Total recovery of radioactivity was $86.1-97.9 \%$. Fig. 1 shows the cumulative micromoles of taurocholate absorbed from the gut and excreted in bile over a 3-5-h period (total excreted, 0.814-0.848 $\mu \mathrm{mol})$. The mean absorption rate calculated from the slope of the linear portion of the curve was 0.468 (range, 0.263-0.574) $\mu \mathrm{mol} / \mathrm{h}$ (Table II). In addition, the

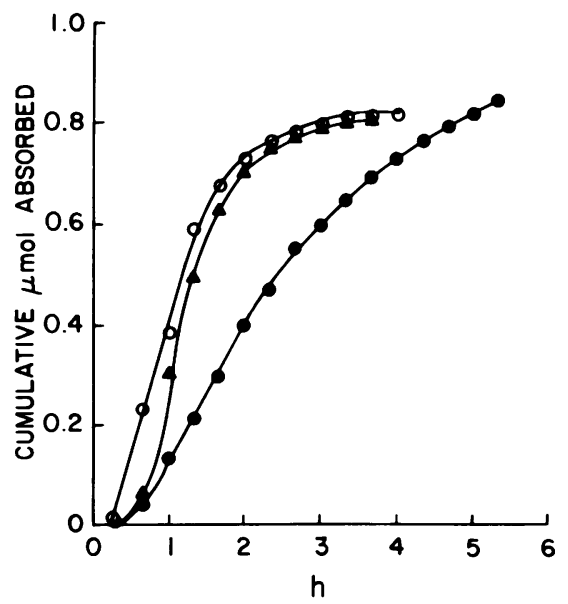

Figure 1 Absorption of $\left[{ }^{14} \mathrm{C}\right]$ taurocholate from fetal intestine. $\left[{ }^{14} \mathrm{C}\right]$ taurocholate was instilled into the fetal intestine at the duodeno-jejunal junction and the cumulative micromoles of $\left[{ }^{14} \mathrm{C}\right]$ taurocholate appearing in fetal bile was measured. $\mathrm{FD}_{1},-0-\mathrm{O}-\mathrm{FD}_{2}, \mathrm{O}-\mathrm{O}-\mathrm{O}, \mathrm{FD}_{3}$, $\boldsymbol{\Delta}-\boldsymbol{\Delta}-\boldsymbol{\Delta}$.

Fetal Intestinal Bile Salt Absorption 
TABLE II

Rate of Taurocholate Absorption from Fetal Intestine in Instillation Experiments

\begin{tabular}{|c|c|c|}
\hline \multicolumn{3}{|c|}{ Absorption rate } \\
\hline Whole gut, $F D_{1-3}$ & Jejunum, $F_{4-8}$ & Ileum, $F_{9-11}$ \\
\hline $\mu \mathrm{mol} / \mathrm{h} / \mathrm{wh}$ ole gut* & \multicolumn{2}{|c|}{$\mu \mathrm{mol} / \mathrm{h} / 10-\mathrm{cm}$ segment length* } \\
\hline 0.263 & 0.344 & 0.444 \\
\hline 0.574 & 0.323 & 0.328 \\
\hline 0.566 & 0.285 & 0.270 \\
\hline - & 0.194 & - \\
\hline- & 0.263 & - \\
\hline $0.468 \pm 0.102 \ddagger$ & $0.282 \pm 0.026 \ddagger$ & $0.347 \pm 0.051 \ddagger$ \\
\hline
\end{tabular}

* Absorption rate, calculated from linear portion of cumulative absorption curve.

$\$$ Mean \pm SEM.

distribution of unabsorbed $\left[{ }^{14} \mathrm{C}\right]$ taurocholate was examined by dividing the small bowel into five segments and analyzing each for radioactivity. More than $90 \%$ of the radiolabel remaining in the gut was found in the proximal two segments, but measurable amounts of radiolabel were recovered as far distally as the fourth segment.

$1 \mathrm{ml}$ of $1 \mathrm{mM}$ sodium $\left[{ }^{14} \mathrm{C}\right]$ taurocholate was instilled into separate closed segments of jejunum and ileum. Total absorption during the 3-4-h period of observation equalled $75.3 \pm 3.9$ and $93.4 \pm 3.7 \%$ in jejunum and ileum, respectively $(P<0.05)$. The mean jejunal and ileal absorption rates calculated from the linear portions of the curves, although greater for the ileum, were not significantly different (jejunum, $0.282 \pm 0.026 \mu \mathrm{mol} / \mathrm{h}$ per 10 - $\mathrm{cm}$ segment length, and ileum $0.347 \pm 0.051)(P>0.2)$ (Table II).

Perfusion experiments, $F D_{12-18}$. Four jejunal and three ileal segments were each perfused with three different concentrations of $\left[{ }^{14} \mathrm{C}\right]$ taurocholate $(0.4,1.0$, and $4.0 \mathrm{mM}$ ) and absorption was determined. Absorption never exceeded $7 \%$ of the perfused taurocholate during any period and polyethylene glycol concentrations remained constant throughout the period of study; thus, the concentration of taurocholate in the perfusate is considered to have remained constant. Absorption is represented graphically for jejunum and ileum in Figs. 2 and 3. Linearity was attained 20-60 min after the beginning of perfusion, and usually was maintained until the study was terminated. Absorption rates were derived from the linear portions of each curve $(r>0.99)$ (Table III). Mean jejunal and ileal absorption rates were not statistically different at perfusion concentrations of 0.4 and $1.0 \mathrm{mM}$ $(P>0.2)$. With $4.0 \mathrm{mM}$ perfusate, however, jejunal absorption exceeded ileal absorption $(P<0.05)$ (Table III).

Absorption rate is plotted against perfusate concentration in Fig. 4. In all but one instance $\left(\mathrm{FD}_{16}\right.$, ileal perfusion), both jejunal and ileal absorption rates increased linearly with increasing perfusion con-

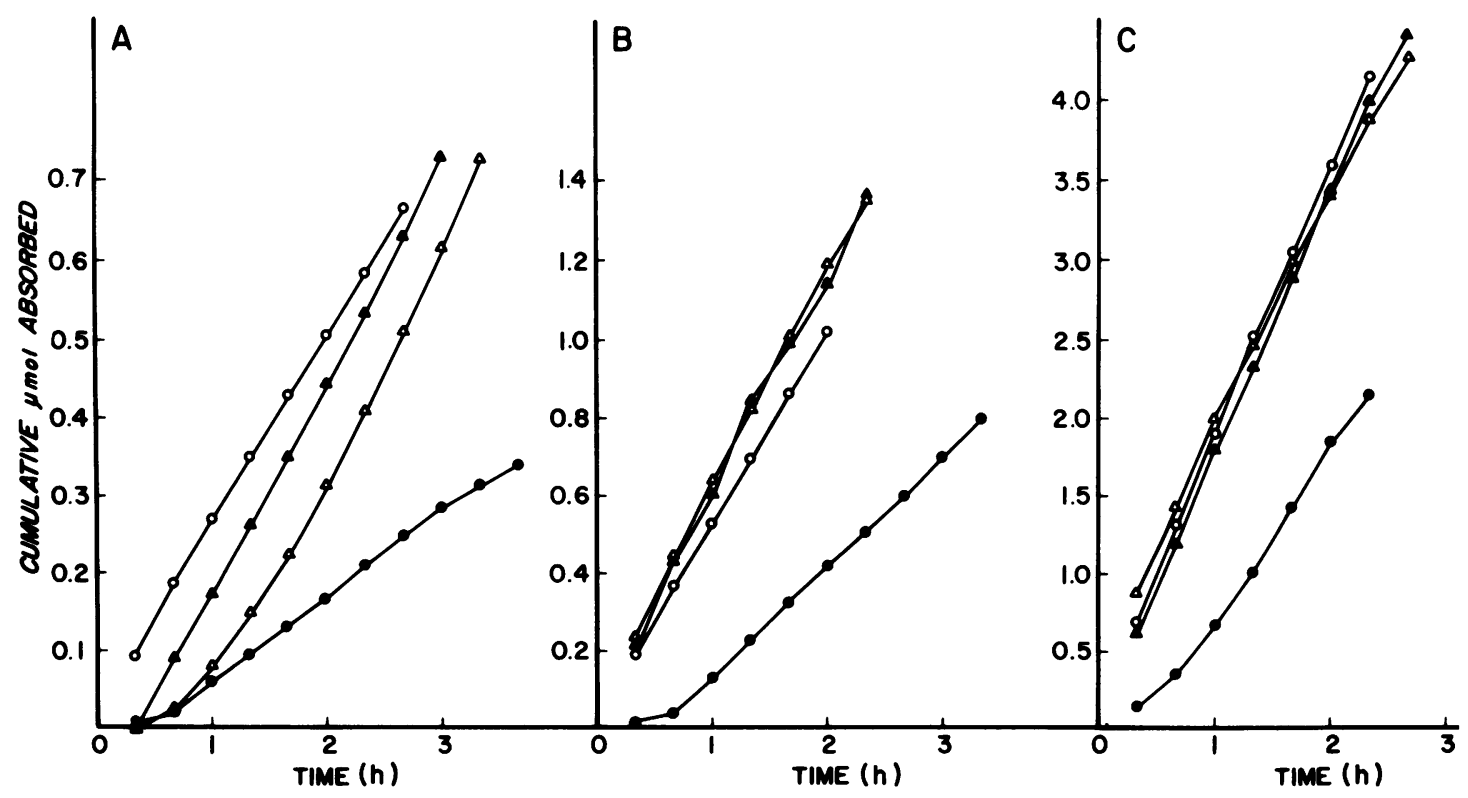

FIGURE 2 Absorption of $\left[{ }^{14} \mathrm{C}\right]$ taurocholate from perfused fetal jejunum. Three concentrations of taurocholate $(\mathrm{A}, 0.4 \mathrm{mM}, \mathrm{B}, 1.0 \mathrm{mM}$, and $\mathrm{C}, 4.0 \mathrm{mM}$ ) were perfused through jejunal segments and the rate of appearance of absorbed bile salt was measured. FD $_{12},-0-0$, $\mathrm{FD}_{13}, \mathrm{O}-\mathrm{O}-\mathrm{O}, \mathrm{FD}_{14}, \Delta-\Delta-\Delta$, and $\mathrm{FD}_{15}, \mathbf{\Delta}-\mathbf{\Delta}-\mathbf{\Delta}$. 


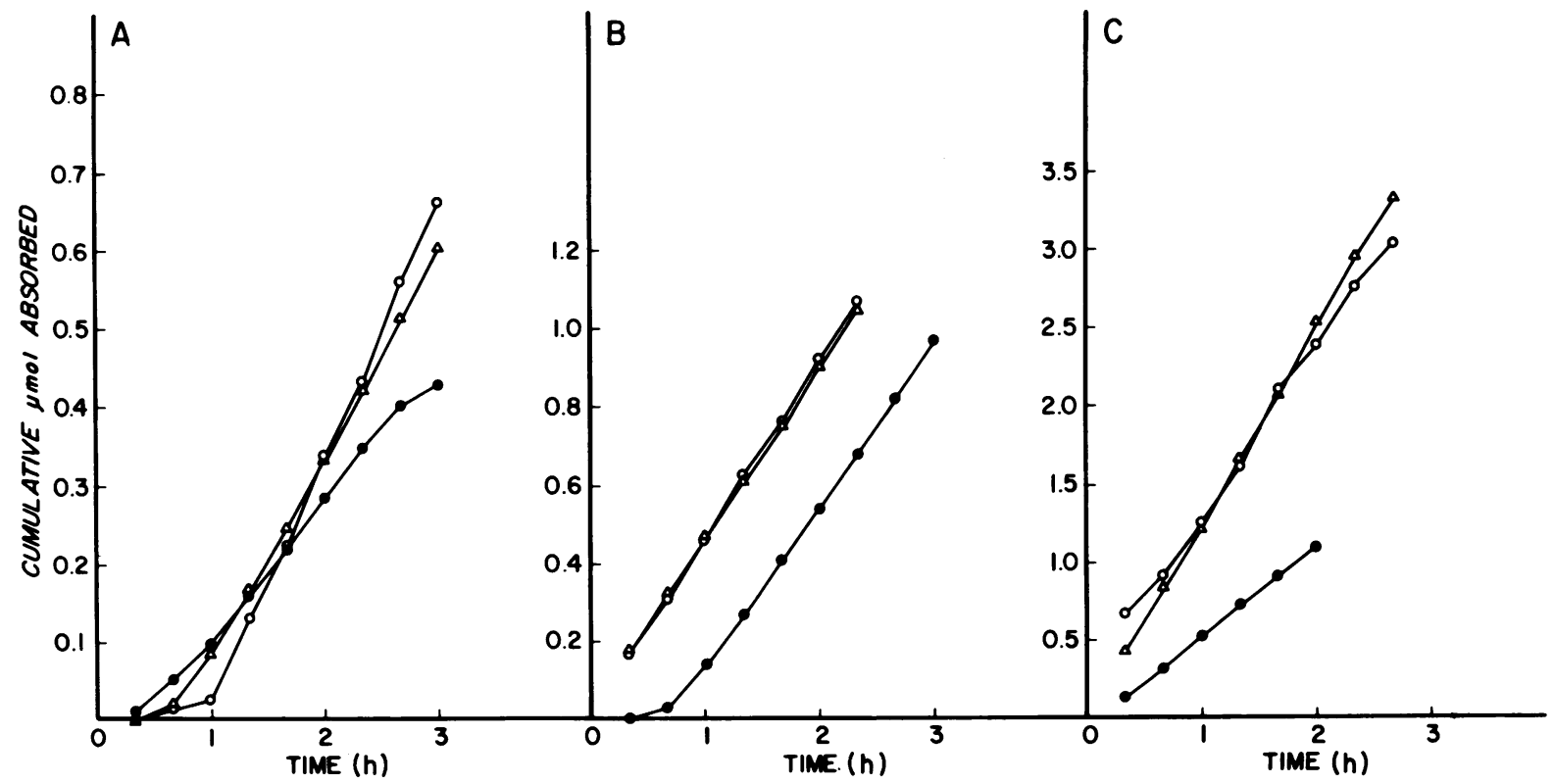

FIGURE 3 Absorption of $\left[{ }^{14} \mathrm{C}\right]$ taurocholate from perfused fetal ileum. Details of perfusion and concentrations of perfusate $(A, B$, and $C)$ as in Fig. 2. FD $16,-F_{17}$, $\mathrm{O}-\mathrm{O}-\mathrm{O}$, and $\mathrm{FD}_{18}, \Delta-\Delta-\Delta$.

centration $(r>0.98)$. In ileal perfusion $\mathrm{FD}_{16}$, the rate of absorption obtained with $4.0 \mathrm{mM}$ perfusate diverged markedly from linearity.

The radiolabel in all bile samples from animals included in the perfusion and instillation studies was analyzed by thin-layer chromatography on silica gel $\mathrm{G}$ in three solvent systems. $90-95 \%$ of the radiolabel migrated on the chromotograms coincident with standard purified taurocholate. The remaining 5$10 \%$ was distributed evenly over the plates. Histological examination of the intestinal segments from both instillation and perfusion studies by light microscopy was unremarkable.

In vitro experiments, $F D_{19-32}$. Preliminary everted gut sac studies $\left(\mathrm{FD}_{19-21}\right)$ were performed to establish the functional viability of the tissue preparations. Concentrations of glucose in the serosal fluid were $4.0 \pm 1.0$ and $1.6 \pm 0.2$ times the incubation fluid concentrations in fetal jejunal and ileal sacs incubated for $1 \mathrm{~h}$. Measurements of mucosal uptake of $\left[{ }^{3} \mathrm{H}\right]-$ taurocholate failed to reveal a significant difference between jejunum and ileum.

Everted gut rings prepared from fetal jejunum and ileum were incubated with $0.003-0.3 \mathrm{mM}\left[{ }^{3} \mathrm{H}\right]$ taurocholate $\left(\mathrm{FD}_{22-32}\right)$. At the end of $1 \mathrm{~h}$, the ratio of mucosal taurocholate concentration (nanomoles/gram wet weight of tissue) to incubation medium taurocholate concentration (nanomoles/gram medium) was determined (Table IV). Whereas individual mucosal/incubation fluid $\left[{ }^{3} \mathrm{H}\right]$ taurocholate concentration ratios varied, mean values for jejunum and ileum were not significantly in excess of unity at any concentration. Although mean ileal ratios were consistently higher, no matched comparison at any concentration showed a statistically significant difference. In contrast, controlled studies of adult ileal everted

TABLE III

Rate of Taurocholate Absorption from Fetal Intestine in Perfusion Experiment

\begin{tabular}{ccc}
\hline \multirow{2}{*}{$\begin{array}{c}\text { Concentration of } \\
\text { perfusate }\end{array}$} & \multicolumn{2}{c}{ Absorption rate } \\
\cline { 2 - 3 }$m M$ & Jejunum, $\mathrm{FD}_{\mathbf{1 2}-1 \mathrm{1}}$ & Ileum, $\mathrm{FD}_{\mathbf{1 6 - 1 8}}$ \\
\hline & 0.116 & 0.183 \\
& 0.240 & 0.318 \\
& 0.288 & 0.264 \\
& 0.282 & - \\
& $0.232 \pm 0.040^{*}$ & $0.255 \pm 0.039^{*}$ \\
& 0.281 & 0.406 \\
1.0 & 0.488 & 0.438 \\
& 0.546 & 0.450 \\
& 0.546 & - \\
& $0.470 \pm 0.065^{*}$ & $0.431 \pm 0.013^{*}$ \\
& 1.120 & 0.605 \\
4.0 & 1.730 & 1.250 \\
& 1.460 & 1.120 \\
& 1.660 & $0.992 \pm 0.200^{*}$ \\
\hline
\end{tabular}

* Mean \pm SEM.

Fetal Intestinal Bile Salt Absorption 

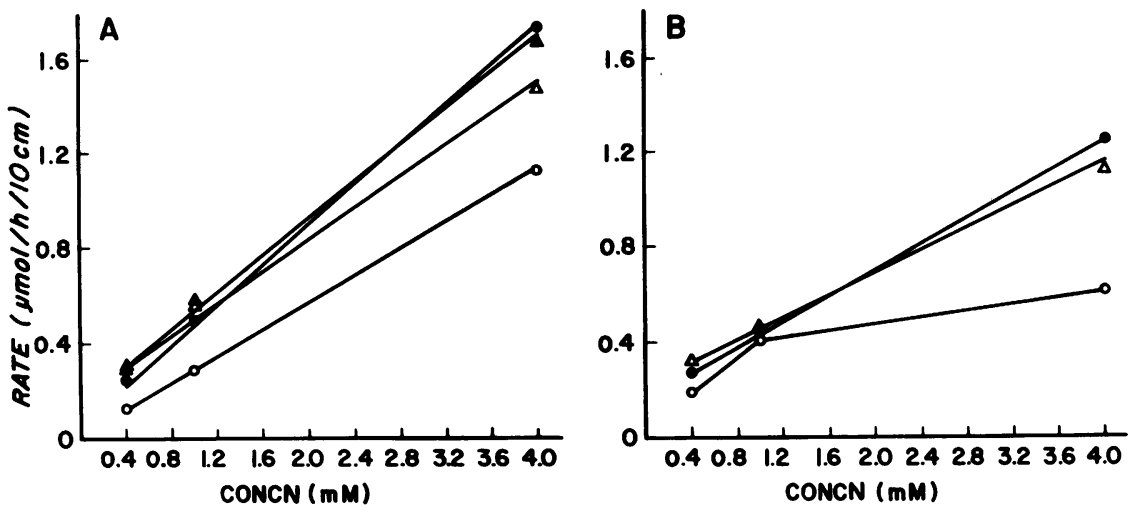

FIGURE 4 Change of rate of absorption of $\left[{ }^{14} \mathrm{C}\right]$ taurocholate from fetal jejunum (A) and ileum (B) with increasing concentrations of perfusate. Symbols for individual experiments as in Figs. 2 and 3.

gut rings $\left(\mathrm{AD}_{1-10}\right)$ showed mean mucosal/incubation fluid ratios of $4.58 \pm 0.28,4.00 \pm 0.24$, and $2.11 \pm 0.07$ at $0.003,0.03$, and $0.3 \mathrm{mM}\left[{ }^{3} \mathrm{H}\right]$ taurocholate concentrations in incubation fluid (Table IV).

Experiments on neonatal dogs, $N D_{1-12}$. Everted rings were prepared from the proximal jejunum and terminal ileum of newborn puppies, age 1-5 wk, and taurocholate absorption was measured as described above. As shown in Table IV, mucosal/incubation medium ratios were less than unity at 1 wk of age. Values in excess of unity were obtained at $2 \mathrm{wk}$ of age in two out of four studies. At $5 \mathrm{wk}$, all values of the mucosal-incubation medium ratios were in excess of unity, and the concentration mechanism appeared to have reached adult levels.

TABLE IV

Absorption of Taurocholate by Everted Gut Rings*

\begin{tabular}{|c|c|c|c|}
\hline & \multicolumn{3}{|c|}{ Taurocholate concentration } \\
\hline & $0.003 \mathrm{mM}$ & $0.03 \mathrm{mM}$ & $0.3 \mathrm{mM}$ \\
\hline \multicolumn{4}{|l|}{ Fetus, FD $_{22-32}$} \\
\hline Jejunum & $0.83 \pm 0.11$ & $0.81 \pm 0.07$ & $0.76 \pm 0.07$ \\
\hline Ileum & $1.04 \pm 0.09$ & $0.93 \pm 0.07$ & $0.81 \pm 0.06$ \\
\hline Neonate, $\mathrm{ND}_{1-12}$ & \multicolumn{3}{|c|}{$1 \mathrm{Wk}, \mathrm{ND}_{1-4}$} \\
\hline Jejunum & $0.84 \pm 0.04$ & $0.84 \pm 0.04$ & $0.79 \pm 0.03$ \\
\hline Ileum & $1.00 \pm 0.11$ & $\begin{array}{c}0.84 \pm 0.06 \\
2 \mathrm{Wk}, \mathrm{ND}_{5-8}\end{array}$ & $0.86 \pm 0.04$ \\
\hline Jejunum & $1.14 \pm 0.12$ & $1.24 \pm 0.08$ & $0.96 \pm 0.03$ \\
\hline Ileum & $3.05 \pm 0.69$ & $2.80 \pm 0.64$ & $1.24 \pm 0.22$ \\
\hline & $\because 6$ & $5 \mathrm{Wk}, \mathrm{ND}_{9-12}$ & \\
\hline Jejunum & $0.87 \pm 0.03$ & $0.86 \pm 0.08$ & $0.53 \pm 0.02$ \\
\hline Ileum & $6.93 \pm 0.68$ & $6.92 \pm 0.61$ & $3.10 \pm 0.14$ \\
\hline Adult, $\mathrm{AD}_{1-10}$ & & & \\
\hline Jejunum & $0.51 \pm 0.05$ & $0.48 \pm 0.04$ & $\begin{array}{l}0.38 \pm 0.02 \\
2.11+0.27\end{array}$ \\
\hline Ileum & $4.58 \pm 0.28$ & $4.00 \pm 0.24$ & $2.11 \pm 0.27$ \\
\hline
\end{tabular}

* Results are expressed as mean $\pm \mathrm{SEM}$ of mucosal/incubation medium ratio. See text.

\section{DISCUSSION}

The present study provides a direct in vivo demonstration of fetal intestinal absorption of the major bile salt found in the fetal dog, taurocholate. Taurocholate absorption was shown to occur from uninterrupted fetal gut, as well as from individually cannulated segments of jejunum and ileum with intact blood supply. Moreover, absorption was demonstrable over a 10-fold concentration range, embracing values present in the fetal intestinal lumen under physiological conditions.

In sharp contrast to the familiar adult pattern, however, fetal jejunal bile salt absorption was of the same order of magnitude as ileal absorption. According to the best available approximation, the $\mathrm{pK}_{\mathrm{a}}$ of taurocholate equals 1.85 (15), thus insuring virtually complete ionization of the molecule at luminal $\mathrm{pH}$ 's. Passive ionic absorption is limited in the adult, but conservation of intestinal taurocholate is promoted by a mechanism of active bile salt transport localized in the terminal ileum (1). In the present study of the dog fetus, when $1 \mathrm{mM}$ taurocholate was instilled into closed jejunal and ileal sacs with blood supply intact, the mean maximal absorption rate equalled 0.282 \pm 0.026 and $0.347 \pm 0.051 \mu \mathrm{mol} / \mathrm{h}$ per 10 -cm segment jejunum and ileum, respectively. Although the ileal absorption rate was greater, the difference was not statistically different $(P>0.2)$. Similarly, when open jejunal and ileal segments were perfused with two concentrations of taurocholate $(0.4$ and $1.0 \mathrm{mM})$, the mean rates of taurocholate absorption were nearly identical for the two segments. At the highest concentration studied $(4.0 \mathrm{mM})$, jejunal absorption actually exceeded ileal absorption. Previous studies using comparable techniques in dogs (16) and other species (17) have shown ileal-jejunal differences of 6to 30 -fold. The results of the present study thus show that the fetal ileal absorptive mechanism is de- 
fective. This view is confirmed by the finding that, in all fetal studies but one, incremental increases in perfusion concentration in any given segment produced linear increases in absorption rate. The absence of any suggestion of saturation kinetics (18) confirms the hypothesis that jejunal and ileal absorption were by passive mechanisms, although a mechanism saturated at concentrations below those examined in vivo cannot be excluded.

The absorption of taurocholate was studied in adult and fetal everted gut rings and sacs $(19,20)$. Glucose transport against concentration gradients was demonstrable for both the jejunum and ileum under the conditions of study, suggesting that the tissue preparations were functionally intact. Whereas mucosal/incubation medium taurocholate concentration ratios in adult ileum were five to eight times as high as jejunal ratios, fetal ileal and jejunal ratios did not differ significantly. Similarly, whereas mucosal uptake in adult ileum demonstrated saturation phenomena at successively higher concentrations over the range studied $(0.003-0.3 \mathrm{mM})$, no evidence of saturation of uptake was demonstrable in fetal ileum.

It was further demonstrated that this defect persisted after birth. Using everted rings of newborn puppy ileum, mucosal concentration of taurocholate was not demonstrable until the second week after birth and did not appear to reach adult levels in all animals studied until a period between 2 and 5 wk of age. At $5 \mathrm{wk}$, saturation phenomena comparable to those demonstrable in adults were evident. Maturation of the mechanism developed in nursing puppies before the time of weaning.

Thus, the ileal mechanism for active bile salt transport is not demonstrable in the near-term fetal $\mathrm{dog}$, although bile salt is passively absorbed from both fetal jejunum and ileum. An enterohepatic circulation of bile salt is directly demonstrable in the dog. With the limited movement of luminal contents along the fetal intestine and the ready absorption of bile salts proximally in the jejunum, it seems likely that fetal ileal absorption is largely bypassed and, in comparison with the adult pathway, the fetal enterohepatic circulation is "short-circuited."

The mechanism of passive absorption from the fetal small bowel remains a matter for speculation. As noted above, passive ionic diffusion would be the predicted mechanism if taurocholate were absorbed intact. Although luminal deconjugation of taurocholate to cholate and passive nonionic diffusion of cholate is not ruled out in these studies, the fetal dog intestine is bacteria free, there was no measurable cholate in the luminal content, and absorption commenced rapidly, all of which militate against this mechanism.

Finally, the broader implications of the study should be entertained. Although extrapolations from the dog to humans should be made with caution, the possibility exists that a similar transport defect may be present in newborn infants. It has only recently come to be appreciated that, especially in premature infants, bile salt pool size, synthesis rate, turnover, and luminal concentration are grossly deficient $(21,22)$, and that these defects, along with defects in pancreatic function, contribute to the development of malabsorption and steatorrhea in neonates fed formula diets $(23,24)$. To complete this picture so that rational management of neonatal nutrition can be instituted, it is now a matter of high priority to establish whether a comparable failure of maturation of intestinal bile salt transport is present in normal and premature infants. Jejunal absorption of bile salt might lower the concentration available proximally, whereas the absence of active ileal transport might permit wastage of that fraction available distally. Failure of intestinal maturation could be an additional contributory factor leading to neonatal malabsorption of fat.

\section{ACKNOWLEDGMENTS}

This work was supported in part by U. S. Public Health Service grants HD08954, AM17847, and HD01385.

\section{REFERENCES}

1. Weiner, I. M., and L. Lack. 1968. Bile salt absorption; enterohepatic circulation. Hndb. Physiol. 3(Sect. 6. Alimentary Canal): 1439-1455.

2. Dietschy, J. M. 1968. Mechanism for the intestinal absorption of bile acids. J. Lipid Res. 9: 297-309.

3. Small, D. M., R. H. Dowling, and R. N. Redinger. 1972. The enterohepatic circulation of bile salts. Arch. Intern. Med. 130: 552-573.

4. Jackson, B. T., R. A. Smallwood, G. J. Piasecki, A. S. Brown, H. F. J. Rauschecker, and R. Lester. 1971. Fetal bile salt metabolism. I. The metabolism of sodium cholate- ${ }^{14} \mathrm{C}$ in the fetal dog. J. Clin. Invest. 50: 1286-1294.

5. Smallwood, R. A., R. Lester, G. J. Piasecki, P. D. Klein, R. Greco, and B. T. Jackson. 1972. Fetal bile salt metabolism. II. Hepatic excretion of endogenous bile salt and of a taurocholate load. J. Clin. Invest. 51: 1388- 1397.

6. Lester, R., B. T. Jackson, and R. A. Smallwood. 1970. Fetal hepatic function. Birth Defects, Orig. Artic. Ser. 6: 16-21.

7. Jackson, B. T., J. P. Clarke, and R. H. Egdahl. 1960. Direct lead fetal electrocardiography with undisturbed fetal-maternal relationships. Surg. Gynecol. Obst. 110: $687-692$.

8. Jackson, B. T., and R. H. Egdahl. 1960. The performance of complex fetal operations in utero without amniotic fluid loss or other disturbances of fetalmaternal relationships. Surgery (St. Louis). 48: 564-570.

9. Dowd, S. R., and J. M. Little. 1976. Preparation of lauryl-sarcosyltaurine: a surface active constituent of crab gastric juice. J. Lipid Res. 17: 154-155.

10. Eneroth, P. 1969. Thin-layer chromatography of bile alcohols and bile acids. In Lipid Chromatographic Analysis. G. V. Marinetti, editor. Marcel Dekker, Inc., New York. II: 154. 
11. Lester, R., and R. Schmid. 1963. Intestinal absorption of bile pigments. I. The enterohepatic circulation of bilirubin of the rat. J. Clin. Invest. 42: 736-746.

12. Borgström, B., A. Dahlqvist, G. Lundh, and J. Sjövall. 1957. Studies of intestinal digestion and absorption in the human. J. Clin. Invest. 36: 1521-1536.

13. Kingsley, G. R., and G. Getchell. 1960. Direct ultramicro glucose oxidase method for determination of glucose in biological fluids. Clin. Chem. 6: 475-466.

14. Olsen, W. A., and I. H. Rosenberg. 1970. Intestinal transport of sugars and amino acids in diabetic rats. J. Clin. Invest. 49: 96-105.

15. Small, D. M. 1971. The physical chemistry of cholanic acids. In The Bile Acids. Vol. I. Chemistry. P. P. Nair and D. Kritchevsky, editors. Plenum Publishing Corporation, New York. 289.

16. Glasser, J. E., I. M. Weiner, and L. Lack. 1965. Comparative physiology of intestinal taurocholate transport. Am. J. Physiol. 208: 359-362.

17. Schiff, E. R., N. C. Small, and J. M. Dietschy. 1972. Characterization of the kinetics of the passive and active transport mechanisms for bile acid absorption in the small intestine and colon of the rat. J. Clin. Invest. 51: 1351-1362.

18. Dietschy, J. M. 1970. Difficulties in determining valid rate constants for transport and metabolic processes. Gastroenterology. 58: 863-874.

19. Lack, L., and I. M. Weiner. 1961. In vitro absorption of bile salts by small intestine of rats and guinea pigs. Am. J. Physiol. 200: 313-317.

20. Playoust, M. R., and K. J. Isselbacher. 1964. Studies on the transport and metabolism of conjugated bile salts by intestinal mucosa. J. Clin. Invest. 43: 467-476.

21. Watkins, J. B., D. Ingall, P. Szczepanik, P. D. Klein, and R. Lester. 1973. Bile-salt metabolism in the newborn. Measurement of pool size and synthesis by stable isotope technic. N. Engl. J. Med. 288: 431-434.

22. Watkins, J. B., P. Szczepanik, J. B. Gould, P. Klein, and R. Lester. 1975. Bile salt metabolism in the human premature infant. Preliminary observations of pool size and synthesis rate following prenatal administration of dexamethasone and phenobarbital. Gastroenterology. 69: 706-713.

23. Fomon, S. J., E. E. Ziegler, L. N. Thomas, R. L. Jensen, and L. J. Filer, Jr. 1970. Excretion of fat by normal full-term infants fed various milks and formulas. Am. J. Clin. Nutr. 23: 1299-1313.

24. Watkins, J. B., C. M. Bliss, R. M. Donaldson, Jr., and R. Lester. 1974. Characterization of newborn fecal lipid. Pediatrics. 53: 511-515. 